\title{
DINAMIKA NILAI TUKAR : INTERVENSI KEBIJAKAN DALAM RANGKA PENINGKATAN KESEJAHTERAAN NELAYAN DAN PEMBUDIDAYA IKAN
}

\author{
Armen Zulham, Subhechanis Saptanto, Maharani Yulisti, dan Lindawati \\ Balai Besar Riset Sosial Ekonomi Kelautan dan Perikanan \\ JI. KS. Tubun Petamburan VI Jakarta 10260 \\ Telp. (021) 53650162, Fax. (021)53650159 \\ Diterima 4 Februari 2011 - Disetujui 21 Mei 2011
}

\begin{abstract}
ABSTRAK
Nilai Tukar Rumah Tangga Perikanan (NTP) merupakan salah satu indikator ekonomi yang digunakan untuk melihat perkembangan kesejahteraan nelayan dan pembudidaya ikan. Indeks NTP mengambarkan proporsi harga yang diterima (IT) dan harga yang dibayar (IB) rumah tangga nelayan dan pembudidaya ikan. Penelitian ini bertujuan untuk menganalisis faktor-faktor yang mempengaruhi dinamika nilai tukar dalam perspektif intervensi kebijakan peningkatan kesejahteraan nelayan dan pembudidaya ikan. Metode penelitian yang digunakan adalah metode desk study dengan menggunakan data sekunder yang diterbitkan oleh Badan Pusat Statistik (BPS). Data yang digunakan adalah data bulanan indeks NTP periode 2008-2009. Metode analisis data menggunakan pendekatan ekonometrik persamaan regresi berganda. Hasil penelitian menunjukkan bahwa inflasi dan nilai tukar rupiah merupakan faktor yang sangat berperan dalam mempengaruhi indeks NTP dengan $R^{2}=0,90$. Hal itu berarti harga barang konsumsi, harga faktor produksi dan harga output sangat berperan dalam indeks NTP. Dengan demikian informasi tersebut dapat menjadi bahan rekomendasi bagi pemerintah untuk melakukan intervensi kebijakan dalam rangka meningkatkan kesejahteraan nelayan dan pembudidaya ikan
\end{abstract}

Kata kunci: nilai tukar perikanan, nelayan, pembudidaya ikan

\section{Abstract : Dynamics of Term of Trade : The Policy Intervention for Increasing Welfare of Fishers and Fish Farmers by : Armen Zulham, Subhechanis Saptanto, Maharani Yulisti, and Lindawati}

Fisheries term of trade (NTP) is one of economic indicators usually use to measure the economic welfare of fishers and fish farmers. The NTP index represents the proportion of price received (IT) and price paid by fishers and fish farmers (IB). This research aims to analyze factors causing dynamic of term of trade in relation to policy intervention for increasing welfare of fishers and fish farmer. This research applied desk study method by analyzing secondary data of the Central Bureau of Statistics (BPS). This research used the monthly fisheries term of trade data for $2008-2009$ period. An econometric approach with a quadratic regression model was used in this study. Results show that inflation an exchanger ate of IDR were an important factors enfluencing NTP index with $R^{2}$ of 0,90 . These mean that consumable good prices input price and output price play an important role in the NTP index. Thus, they can be used as basis for policy formulation by goverment in relation to improving welfare of fishers and fish farmer.

Keywords : fisheries term of trade value, fishers, fish farmers 


\section{PENDAHULUAN}

Pada tahun 2007 jumlah rumah tangga perikanan (RTP) yang ekonominya tergantung pada perikanan tangkap mencapai 958.499 RTP atau setara dengan jumlah nelayan 2.755.794 orang. Rumah tangga yang tergantung pada kegiatan budidaya perikanan sebanyak 1.338.758 RTP atau setara dengan 2.344.183 orang. Pada tahun 2008 jumlah RTP perikanan tangkap menurun menjadi 939.016 RTP dan RTP pembudidaya ikan sekitar 1.359.053 RTP (BPS, 2010).

Kontribusi perikanan dalam PDB nasional 2006 - 2009 rata-rata sekitar 2,2\%, sedangkan kontribusi perikanan terhadap PDB nasional tanpa migas 2,4\%. PDB sektor perikanan dengan harga konstan tahun 2000 meningkat dari Rp. 41.419 milyar tahun 2006 menjadi Rp. 48.253 miliar pada tahun 2009 dengan laju pertumbuhan $3,8 \%$ per tahun. Peningkatan tersebut dipacu melalui berbagai program pembangunan dengan tujuan untuk mendorong peningkatan produksi perikanan, pendapatan, dan penyediaan lapangan kerja dalam rangka mewujudkan visi dan misi yang telah dicanangkan oleh Kementerian Kelautan dan Perikanan.

Dampak dari program pembangunan perikanan terhadap kehidupan dan perilaku nelayan dan pembudidaya sebagai produsen komoditas perikanan dapat diukur melalui berbagai pendekatan. Salah satu pendekatan adalah melalui indeks nilai tukar perikanan (NTP). Menurut Simatupang dan Maulana (2007), konsep pengukuran nilai tukar relatif sederhana, diukur sebagai rasio indeks harga yang diterima dan indeks harga yang dibayar petani sehingga mudah dipahami oleh masyarakat umum. Konsep nilai tukar di Indonesia dikembangkan oleh Badan Pusat Statistik sejak tahun 1983 terhadap rumah tangga pertanian tanaman pangan di Pulau Jawa dan sejak tahun 1987 dikembangkan di luar Pulau Jawa, nilai tukar ini digunakan sebagai salah satu alat monitoring dan perencanaan pembangunan khususnya untuk sektor pertanian (Rahmat, 2000). Pengukuran indeks NTP itu memberi pemahaman tentang daya tukar (purchasing power) dari rumah tangga perikanan terhadap produk non perikanan.

Nilai tukar perikanan merupakan indikator penting dalam menilai keberhasilan pembangunan perikanan serta menyusun strategi untuk meningkatkan produksi, pendapatan dan daya saing usaha perikanan. Nilai tukar perikanan tidak hanya dipengaruhi oleh kinerja sektor perikanan, namun juga dipengaruhi oleh kebijakan di luar sektor kelautan dan perikanan. Berdasarkan pemikiran tersebut maka tujuan dari tulisan ini adalah untuk mencari faktorfaktor yang mempengaruhi dinamika nilai tukar sehingga dapat dilakukan intervensi kebijakan dalam rangka peningkatan kesejahteraan nelayan dan pembudidaya ikan.

\section{METODOLOGI}

\section{Landasan Teoritis dan Kerangka Pemikiran}

Studi nilai tukar pertanian di Indonesia telah banyak dilakukan khususnya untuk sektor pertanian seperti nilai tukar barter, faktorial dan penerimaan. Seperti studi yang telah dilakukan oleh Soeharjo (1976), nilai tukar barter tentang perdagangan oleh Anwar et al., (1981), nilai tukar barter oleh Sukarja (1981), nilai tukar subsisten dan penerimaan oleh Pramonosidhi (1984), nilai tukar barter, faktorial,dan penerimaan oleh Reksasudharma (1988), nilai tukar barter oleh Simatupang (1992) dan nilai tukar petani dan barter oleh Hutabarat (1995).

Menurut Hutabarat (1995), nilai tukar produk primer dapat digunakan sebagai indikator kesejahteraan rumah tangga di pedesaan. Indikator ini sangat ditentukan oleh perilaku harga barang dan jasa di pedesaan. Harga produk primer pedesaan umumnya cenderung berfluktuasi dan nilai riilnya menurun. Hipotesis nilai tukar Prebisch-Singer (Prebisch, 1964; Singer, 1984) menunjukkan penurunan nilai tukar dipengaruhi oleh beberapa faktor, seperti: (1) rendahnya elastisitas pendapatan dari produk primer; dan (2) perubahan teknologi pada pengembangan produk primer. 
Beberapa penelitian telah menguatkan hipotesis Prebisch-Singer tersebut, seperti Spraos (1980), Grilli dan Yang (1988), dan Cuddington dan Urzua (1989). Selanjutnya hasil penelitian Simatupang dan Isdijoso (1992), menujukkan bahwa nilai tukar dapat mencerminkan tingkat kesejahteraan pelaku ekonomi di pedesaan.

Indeks NTP merupakan indikator yang dapat digunakan sebagai acuan untuk mengukur efektifitas berbagai kebijakan harga yang diimplementasikan oleh pemerintah terhadap kelompok masyarakat nelayan dan pembudidaya ikan. Efektifitas tersebut diukur dari rasio antara harga barang/jasa yang diterima dengan harga barang dan jasa yang dibayar oleh nelayan dan pembudidaya ikan.

Indeks harga barang dan jasa dihitung dengan pendekatan Laspeyres. Indeks harga yang diterima (IT) merupakan agregasi dari indeks harga yang diterima nelayan (penangkapan) dan indeks harga yang diterima pembudidaya ikan. Indeks harga yang dibayar nelayan dan pembudidaya ikan (IB) adalah agregasi dari indeks harga barang dan jasa yang dikonsumsi rumah tangga dan indeks biaya produksi dan penambahan barang modal.

Indeks harga barang dan jasa yang dikonsumsi rumah tangga merupakan agregasi dari indeks harga bahan makanan, makanan jadi, perumahan, sandang, kesehatan, pendidikan, rekreasi dan olah raga. Sementara itu indeks biaya produksi merupakan agregasi dari indeks harga bibit, obat-obatan dan pupuk, transportasi dan komunikasi, sewa lahan, pajak penambahan barang modal, serta upah buruh. Alur pikir perhitungan NTP nelayan dan pembudidaya ikan dapat dipelajari dari Gambar 1.

Pada Gambar 1 dapat dilihat bahwa untuk menghitung nilai tukar digunakan indeks harga yang diterima (pendapatan) dan indeks harga yang dibayar (pengeluaran rumah

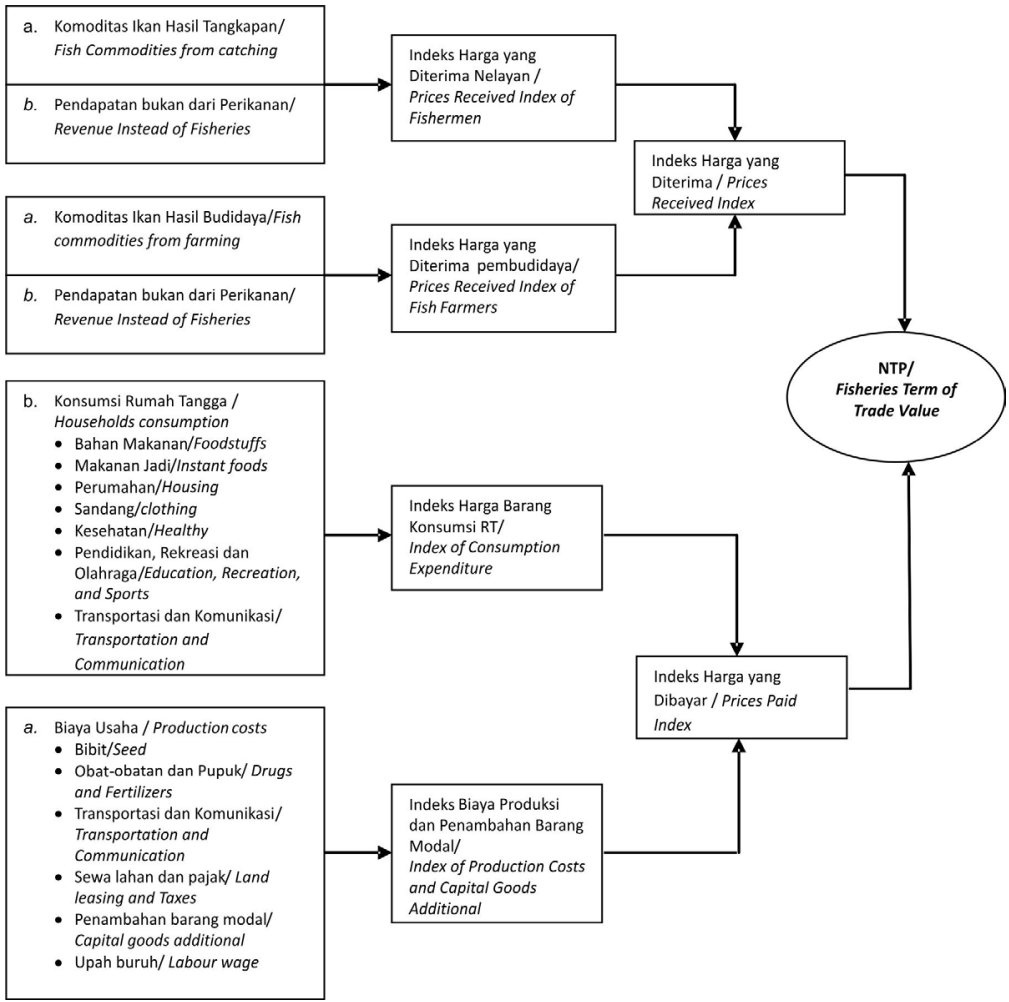

Gambar 1. Alur Perhitungan Indeks Nilai Tukar Perikanan Figure 1. Calculation Flow of Fisheries Term of Trade Value 
tangga). Pendapatan rumah tangga secara umum berasal dari perikanan dan non perikanan. Agregat pendapatan tersebut setelah dilakukan indeksasi kemudian menjadi Indeks harga yang diterima (IT). Agregat pengeluaran rumah tangga untuk pengeluaran usaha, konsumsi dan pengeluaran lain merupakan indeks harga yang dibayar rumah tangga (IB). Rasio antara indeks harga yang diterima dengan indeks harga yang dibayarkan adalah indeks NTP.

\section{Jenis dan Sumber Data}

Data yang digunakan dalam kajian ini adalah data sekunder bulanan (24 bulan) yang dipublikasikan oleh Badan Pusat Statistik (BPS) dari Januari 2008-Desember 2009.

\section{Metode Pengumpulan Data}

Pengumpulan data sekunder dilakukan dengan cara melakukan kajian literatur dari berbagai sumber yang mendukung kegiatan penelitian.

\section{Meode Analisis Data}

Analisis data dilakukan dengan menggunakan persamaan regresi berganda, model regresi yang digunakan telah ditransformasi dalam bentuk Ln, yaitu:

\section{Ln NTP $=\beta 0+\beta 1$ Ln IHK $+\beta 2$ Ln NTRP $+\varepsilon$}

Dimana :

NTP $=$ adalah Indek Nilai Tukar Perikanan/ Fisheries Term of Trade

IHK = adalah Indeks Harga Konsumen/ Consumer Price Index

NTRP = adalah nilai tukar rupiah terhadap dolar Amerika Serikat/ IndonesiaUS Dollar Exchange Rate

$\varepsilon=$ Galat/Error Term

\section{Formulasi Perhitungan Indeks}

\section{Indeks harga yang diterima}

Indeks harga yang diterima nelayan dan pembudidaya ikan dalam penelitian ini mengacu pada formula indeks Laspeyers. Indeks harga yang diterima tersebut merupakan rata-rata aritmatik tertimbang dari harga relatif, atau dapat dituliskan sebagai:

$I T_{t}=\frac{\sum_{i=1}^{n}\left(\frac{p_{i t}}{P_{i t-1}}\right) P_{(i t-1)} q_{i 0}}{\sum_{i=1}^{n} P_{i 0} q_{i 0}} \times 100$

Dimana :

$\mathrm{I}_{\mathrm{Tt}}=$ adalah Indeks harga yang diterima oleh nelayan/pembudidaya pada bulan ke t/Prices Received Index by Fishers/Fish Farmers on month $t$.

$\mathrm{P}_{\text {it }}=$ adalah harga barang ke $\mathrm{i}$ yang diterima nelayan/pembudidaya ikan pada bulan ke $t / G o o d s$ Price of $i$ Received by Fishers /Fish Farmers on month $t$.

$\mathrm{P}_{(\mathrm{it}-1)}=$ adalah harga barang ke $\mathrm{i}$ yang diterima nelayan/pembudidaya ikan pada bulan (t-1)/Goods Price Received by Fishers /Fish Farmers on month (t-1).

$\mathrm{P}_{\mathrm{io}}=$ adalah harga yang diterima nelayan/ pembudidaya ikan pada bulan dasar dari barang i/Price Received by Fishers /Fish Farmers on base month of goods $i$.

$\mathrm{Q}_{\mathrm{io}}=$ adalah kuantitas pada bulan dasar dari barang i yang dijual oleh nelayan dan pembudidaya ikan/Quantity Sold of $i$ by Fishers /Fish Farmers of Goods $i$ on the base month.

$\mathrm{n}=$

adalah jenis barang dihasilkan nelayan/pembudidaya ikan yang tercakup dalam komoditas yang dihitung/ Goods Type Produced of Fishers/Fish Farmers in Counted Commodities.

\section{Indeks harga yang dibayar}

Indeks harga yang dibayar nelayan dan pembudidaya ikan adalah indeks harga yang mengambarkan harga yang dibayar nelayan/ pembudidaya ikan terhadap barang/jasa yang diperlukan. Indeks ini merupakan rata- 
rata aritmatik tertimbang dari harga relatif barang/jasa yang dikonsumsi oleh nelayan/ pembudidaya ikan:

$$
I B_{t}=\frac{\sum_{i=1}^{n}\left(\frac{p_{i t}}{P_{i t-1}}\right) P_{(i t-1)} q_{i 0}}{\sum_{i=1}^{n} P_{i 0} q_{i 0}} \times 100
$$

Dimana :

$\mathrm{I}_{\mathrm{Bt}} \quad=$ adalah Indeks harga yang dibayar oleh nelayan/pembudidaya pada bulan ke t/Prices Paid Index by Fishers /Fish Farmer on month $t$.

$\mathrm{P}_{\text {it }} \quad=$ adalah harga barang ke $\mathrm{i}$ yang dibayar nelayan/pembudidaya ikan pada bulan ke $t / G o o d s$ Price of $i$ Paid by Fishers /Fish Farmer on month $t$.

$\mathrm{P}_{(\mathrm{it}-1)}=$ adalah harga barang ke $\mathrm{i}$ yang dibayar nelayan/pembudidaya ikan pada bulan (t-1)/Goods Price of $i$ Paid by Fishers /Fish Farmer on month (t-1).

$\mathrm{P}_{\text {io }} \quad$ = adalah harga yang dibayar nelayan/ pembudidaya ikan pada bulan dasar dari barang i/Price Paid by Fishers /Fish Farmer on base month of goods $i$

$\mathrm{Q}_{\mathrm{i} 0} \quad=$ adalah kuantitas pada bulan dasar dari barang i yang dibeli oleh nelayan dan pembudidaya ikan/ Quantity Bought by Fishers/Fish Farmer of Goods $i$ on the base month.

$\mathrm{n}=$ adalah jenis barang dihasilkan nelayan/pembudidaya ikan yang tercakup dalam komoditas yang dihitung/ Goods Type Produced by Fishers/Fish Farmer in Counted Commodities.

\section{Indeks Nilai Tukar Perikanan}

Indeks nilai tukar perikanan (NTP) merupakan rasio antara indeks harga yang diterima nelayan/pembudidaya ikan dengan indeks harga yang dibayar nelayan/ pembudidaya ikan pada bulan ke $t$.
Indeks NTP tersebut dapat diformulasikan sebagai berikut:

$$
N T P=\frac{I T}{I B} \times 100
$$

\begin{tabular}{|c|c|}
\hline$N T P_{t}=$ & perikanan \\
\hline & pada bulan ke - $\mathrm{t} /$ Fishe \\
\hline & Term of Trade on month - $t$. \\
\hline$I T_{t}=$ & $\begin{array}{l}\text { adalah indeks harga barang dan } \\
\text { jasa yang diterima oleh nelayan/ } \\
\text { pembudidaya ikan pada bulan ke - } \\
\text { t/Goods and Service Price Received } \\
\text { by Fishers/Fish Farmers Index of } \\
\text { Fisheries on month- } t\end{array}$ \\
\hline
\end{tabular}

\section{Dimana :}

$\mathrm{IB}_{\mathrm{t}}=$ adalah indeks harga barang dan jasa yang dibayar oleh nelayan/ pembudidaya ikan pada bulan ke -t/Goods and Service Price Paid by Fishers/Fish Farmers on month - $t$.

Nilai tukar perikanan (NTP) merupakan rasio antara indeks harga yang diterima nelayan/pembudidaya ikan (IT) dengan indeks harga yang dibayar nelayan/pembudidaya ikan (IB). NTP secara konseptual mengukur kemampuan tukar produk yang dihasilkan nelayan/pembudidaya ikan dengan barang dan jasa yang diperlukan oleh nelayan/ pembudidaya ikan.

Indeks harga yang diterima nelayan/ pembudidaya ikan (IT) dapat dijadikan acuan untuk melihat fluktuasi harga komoditas yang dihasilkan nelayan/ pembudidaya ikan. Sementara itu, indeks harga yang dibayar nelayan/pembudidaya ikan (IB) dapat digunakan untuk melihat fluktuasi harga barang dan jasa yang diperlukan untuk memproduksi barang dan jasa yang dihasilkan oleh nelayan/ pembudidaya ikan.

Dengan demikian NTP dapat menggambarkan 3 kemungkinan, yaitu:

1. NTP > 100 : Kesejahteraan nelayan/ pembudidaya ikan lebih baik 
dibandingkan dengan bulan dasar/ Welfare of Fishers/Fish Farmers on present month is better than base month.

2. NTP $=100:$ Kesejahteraan nelayan/ pembudidaya ikan sama dengan kondisi tahun dasar/Welfare of Fishers/ Fish Farmers on present month is equal with base month.

3. NTP < 100 : Kesejahteraan nelayan/ pembudidaya ikan lebih buruk dari kondisi tahun dasar/Welfare of Fishers/ Fish Farmers on present month is worse than base month.

\section{HASIL DAN PEMBAHASAN}

BPS mengelompokkan indeks harga yang diterima rumah tangga perikanan ke dalam tiga (3) kategori, yaitu: indeks harga yang diterima gabungan (ITG), indeks harga yang diterima nelayan (ITN) dan indeks harga yang diterima pembudidaya ikan (ITBD).
IHTG merupakan perkembangan bulanan ratarata harga yang diterima dari barang dan jasa yang dihasilkan rumah tangga gabungan antara nelayan pembudidaya ikan, ITN atau ITBD merupakan perkembangan bulanan rata-rata harga yang diterima dari barang dan jasa yang dihasilkan rumah tangga nelayan atau pembudidaya ikan. Dinamika perkembangan indeks harga yang diterima bulanan tersebut merepresentasikan perkembangan harga barang dan jasa yang diterima oleh rumah tangga perikanan.

\section{Indeks Harga Rumah Tangga Perikanan (IHRTP)}

Secara umum indeks harga yang diterima rumah tangga perikanan dengan harga dasar tahun 2007 cenderung meningkat terutama pada periode Januari 2008September 2009 dengan laju 0,9 \%/bulan, sedangkan pada periode Oktober 2009 - Juni 2010 menunjukkan kecenderungan lebih stabil dengan laju 0,2\%/bulan (Gambar 2).

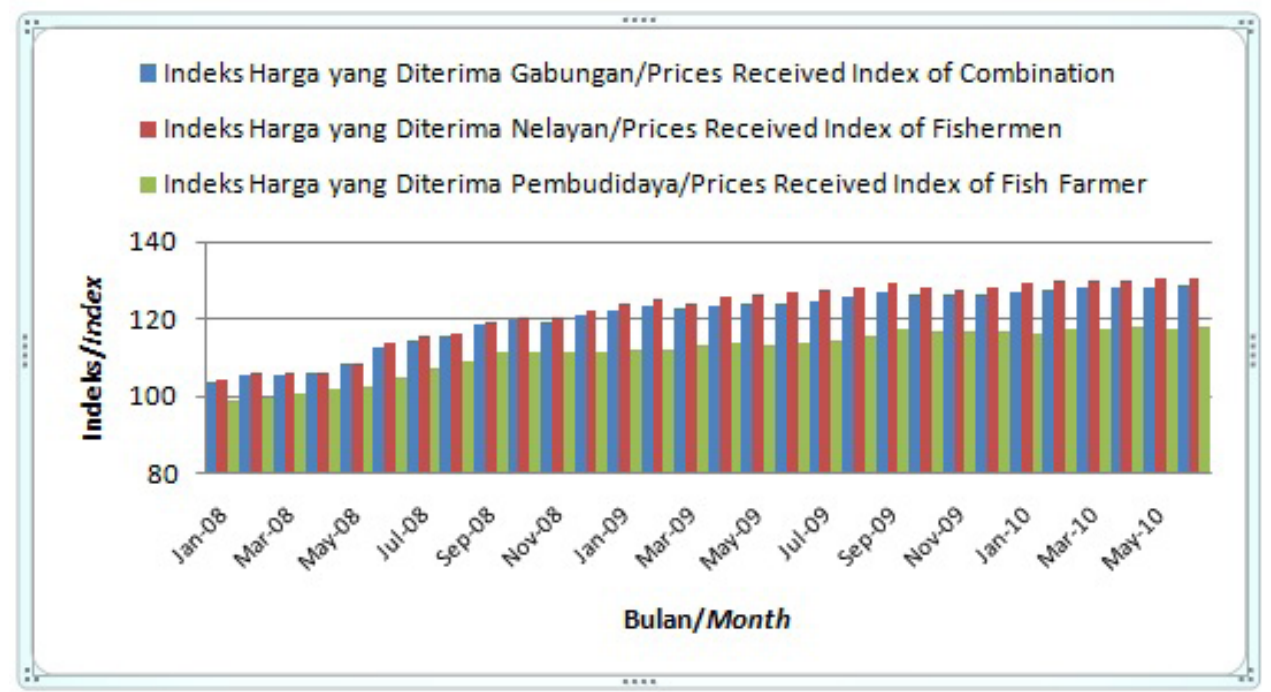

Sumber: BPS (berbagai Terbitan) /

Source : Central Bureau of Statistics-CBS (Various publications)

Gambar 2. Indeks Harga yang Diterima dan Harga yang Dibayar Rumah Tangga Perikanan di Indonesia Januari 2008 - April 2010 (2007 =100).

Figure 2. Prices Received and Prices Paid Index of Fisheries Households in Indonesia, January 2008 - December 2009 (2007 = 100). 
Indeks harga yang diterima pembudidaya ikan lebih rendah dari indeks harga yang diterima nelayan (Gambar 2). Kondisi ini disebabkan oleh pasar ikan hasil tangkapan nelayan lebih luas (domestik dan ekspor). Harga ikan hasil tangkapan nelayan dipengaruhi juga oleh harga ikan komoditas ekspor, seperti harga ikan tuna, cakalang, layur dan beberapa ikan pelagis kecil lainnya. Fluktuasi harga ikan di pasar ekspor diperkirakan akan berpengaruh terhadap harga ikan pada pasar domestik. Harga ikan di pasar ekspor didasarkan pada mata uang dolar Amerika Serikat, sehingga fluktuasi nilai tukar dolar akan mempengaruhi harga ikan yang diterima rumah tangga nelayan.

Peningkatan indeks harga yang diterima rumah tangga perikanan terjadi seiring dengan melemahnya nilai tukar rupiah terhadap dolar Amerika Serikat yang terjadi pada bulan Oktober 2008. Fluktuasi nilai tukar rupiah terhadap Dolar Amerika Serikat terus terjadi sampai bulan September 2009.
Setelah periode tersebut rupiah cenderung menguat sekitar Rp. 9000,- per Dollar Amerika Serikat. Stabilitas nilai tukar Rupiah terhadap Dolar Amerika Serikat diperkirakan ikut menstabilkan indeks harga yang diterima rumah tangga perikanan. Perkembangan Nilai Tukar Rupiah Terhadap Dolar Amerika Serikat Januari 2008 - Desember 2009 dapat dilihat pada Gambar 3 sebagai berikut.

\section{Pengaruh Nilai Tukar Rupiah dan Indek Harga Konsumen (IHK) terhadap Indek Harga Rumah Tangga Perikanan (IHRTP)}

Pengaruh nilai tukar rupiah dan Indeks Harga Konsumen terhadap indeks harga yang diterima gabungan, indeks harga yang diterima nelayan dan indeks harga yang diterima pembudidaya ikan dapat dilihat pada Tabel 1.

Model pada persamaan dalam Tabel 1 menunjukkan sekitar $90 \%$ variabel bebas (independent), variable NTRP dan IHK dapat menjelaskan variabel tidak bebas

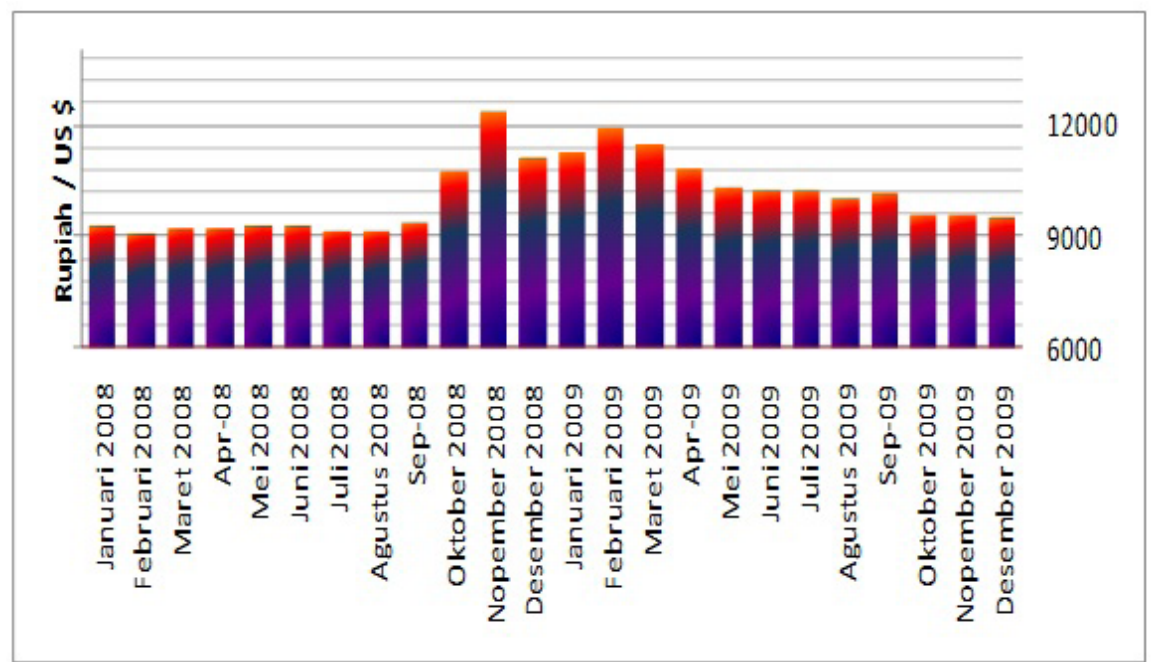

Sumber: BPS (berbagai Terbitan) /

Source: Central Bureau of Statistics-CBS (Various publications)

Gambar 3. Nilai Tukar Rupiah Terhadap US \$ Januari 2008 - Desember 2009

Figure 3. Indonesia Rupiah (IDR) and US Dollar (USD) Exchange Rate, January 2008December 2009 
Tabel 1. Hubungan antara Indek Harga yang Diterima dengan Nilai Tukar Rupiah dan IHK di Indonesia, 2008-2009.

Table 1. The Relationship between the of Prices Received Index with Exchange Rate and CPI in Indonesia, 2008-2009.

\begin{tabular}{|c|c|c|c|c|}
\hline No. & Dependent Variable & Intercept & Independent Variable & $R^{2}$ \\
\hline \multirow[t]{2}{*}{1.} & ITG/Combined Index Of & $-16,5025$ & $0,0003 \mathrm{NTRP}+1,1864 \mathrm{IHK} * * *$ & \\
\hline & Prices Received & $(-1,91)$ & $(13.57)$ & 0,9214 \\
\hline \multirow[t]{2}{*}{2.} & ITN/Prices Received & $-26,7111 *$ & 0,0005 NTRP $+1,2752$ IHK $* * *$ & \\
\hline & Index of Fishers & $(-2,53)$ & $(11,92)$ & 0,9021 \\
\hline \multirow[t]{2}{*}{3} & ITBD/ Prices Received & 7,5113 & $0,0001 \mathrm{NTRP}+0,9351 \mathrm{IHK} * * *$ & \\
\hline & Index of Fish Farmers & $(1,15)$ & $(14,14)$ & 0,9230 \\
\hline
\end{tabular}

Sumber: BPS (berbagai Terbitan)

Sources: Central Bureau of Statistics-CBS (Various publications)

Keterangan: $n=24$. ITG = indeks harga yang diterima gabungan,. ITN = indeks harga yang diterima nelayan, ITBD = Indeks harga yang diterima pembudidaya ikan dan NTRP = nilai tukar rupiah terhadap dolar Amerika Serikat. Persamaan diregresi dalam bentuk natural logaritma (Ln).

Description: $n=24$. ITG = combined index of prices received,. ITN Prices Received Index of Fishermen, ITBD = Prices Received Index of Fish Farmers and NTRP = Exchange rate of Rupiah against the U.S. dollar. The Equation was regressed in the form of natural logarithm (Ln).

(dependent) masing-masing (ITG, ITN, dan ITBD). Pada persamaan pertama, jika IHK meningkat $1 \%$ maka indeks harga yang diterima gabungan (ITG) akan meningkat 1,2\%. Hal ini berarti jika inflasi meningkat 1\% maka harga barang dan jasa yang diterima rumah tangga perikanan akan meningkat 1,2\%. Peningkatan ini berarti dorongan inflasi untuk meningkatkan harga yang diterima nelayan dan pembudidaya ikan relatif kecil namun lebih besar dari dorongannya untuk meningkatkan pengeluaran.

Pada persamaan kedua dalam Tabel 1 menunjukkan setiap peningkatan IHK sebesar $1 \%$ akan mendorong peningkatan penerimaan nelayan sebesar $1,3 \%$. Hal ini berarti setiap kenaikan inflasi akan mendorong peningkatan pendapatan nelayan, karena konsumen harus membayar mahal ikan yang dihasilkan nelayan.

Persamaan ke toga menunjukkan setiap kenaikan IHK sebesar 1\% akan mendorong peningkatan penerimaan pembudidaya ikan (ITBD) sebesar 0,93\%. Hal ini berarti apabila pada tingkat konsumen terjadi peningkatan harga barang dan jasa sebesar
1\% maka pendapatan pembudidaya ikan akan meningkat $0,9 \%$.

Informasi tersebut menunjukkan juga persentase kenaikan penerimaan pembudidaya ikan lebih rendah dari kenaikan penerimaan nelayan. Hal ini terkait dengan orientasi pasar produk yang dihasilkan nelayan dan pembudidaya ikan. Komoditas ikan hasil produksi budidaya lebih banyak dipasarkan untuk pasar domestik, dimana pasarnya terkonsentrasi pada wilayah-wilayah tertentu saja. Komoditas ikan hasil produksi penangkapan sebagian besar dijual ke pasar ekspor. Oleh sebab itu harga ikan hasil budidaya sangat ditentukan oleh volume penawaran dan permintaan ikan pada pasar pasar tersebut. Dengan demikian harga ikan hasil budidaya harganya cenderung lebih rendah dari harga ikan hasil tangkapan di laut.

\section{Faktor Berpengaruh Terhadap Indeks Pengeluaran Rumah Tangga Perikanan (IPRTP)}

Indeks harga yang dibayar merupakan indeks harga gabungan yang dibayar rumah tangga pembudidaya ikan dan nelayan. 
Tabel 2. Hubungan antara laju inflasi dengan Indeks Pengeluaran Rumah Tangga Perikanan di Indonesia, 2008-2009

Table 2. The Relationship between the Rate of Inflation with Fisheries Household Expenditure Index in Indonesia, 2008-2009

\begin{tabular}{crllcr}
\hline No. & \multicolumn{1}{c}{ Dependent Variable } & \multicolumn{1}{c}{ Intercept } & \multicolumn{1}{c}{ Independent Variable } & $\boldsymbol{R}^{\mathbf{2}}$ \\
\hline 1. & IB/Index of Prices Paid & 26,0046 & $0,8102 \mathrm{IHK} * * *-0,0002 \mathrm{NTRP}$ & 0,9866 \\
& & $(11,43)$ & $(35,2)$ & $(-1,06)$ & \\
2. & IK/Index for Consumption & $17,9107 *$ & $0,9019 \mathrm{IHK} * * *-0,0001 \mathrm{NTRP}$ & 0,9272 \\
& Expenditure & $(2,93)$ & $(14,61)$ & $(-0,39)$ & \\
3 & IPD/ Index of Expenditures & $36,0136^{*}$ & $0,6829 \mathrm{IHK} * * *-0001 \mathrm{NTRP}$ & \\
& for Production & $(12,96)$ & $(24,29)$ & $(-0,81)$ & 0,9722 \\
\hline
\end{tabular}

Sumber: BPS (berbagai Terbitan)

Sources: Central Bureau of Statistics-CBS (Various publications)

Keterangan: $\mathrm{n}=24$. IB = indeks harga yang dibayar (Total Pengeluaran),. IK = indeks pengeluaran untuk Konsumsi, IPD = Indeks pengeluaran untuk produksi dan IHK = Indeks Harga Konsumen, NTRP = Nilai Tukar Rupiah.

Description: $n=24$. IB = Prices Paid Index (total expenditure). $I K=$ Index for Consumption Expenditure, IPD $=$ Index of Expenditures for Production and $\mathrm{CPI}=$ Consumer Price Index, NTRP = Exchange Rate

Indeks harga yang dibayar menunjukkan perkembangan harga-harga yang terkait dengan perekonomian dari rumah tangga perikanan. Indeks harga yang dibayar oleh rumah tangga perikanan terkait dengan perkembangan inflasi. Jika inflasi meningkat maka pengeluaran rumah tangga akan meningkat untuk membiayai kebutuhannya.

Model pada Tabel 2 menunjukkan pengaruh IHK yang merupakan proksi dari inflasi terhadap pengeluaran rumah tangga perikanan sangat signifikan. Ketiga model pada Tabel 2 menunjukkan kontribusi/ pengaruh IHK dan NTRP terhadap IB, IK dan IPD cukup tinggi (lebih besar dari 90\%). Peubah bebas (IHK dan nilai tukar rupiah) lebih dari $90 \%$ berperan mempengaruhi harga yang dibayar (IB, IK dan IPD) nelayan/ pembudidaya ikan. Pengaruh indeks harga konsumen (IHK)/inflasi terhadap pengeluaran total rumah tangga sangat signifikan $(0,8102)$, artinya jika inflasi meningkat $1 \%$ maka pengeluaran rumah tangga perikanan akan meningkat $0,8 \%$. Jika inflasi naik sebesar $1 \%$ maka indeks pengeluaran untuk konsumsi akan meningkat $0,9 \%$ dan indeks pengeluaran untuk produksi akan bertambah sebesar $0,6 \%$.
Pengeluaran rumah tangga yang paling dominan adalah pengeluaran untuk konsumsi, sedangkan pengeluaran untuk produksi relatif kecil. Jika ditelusuri lebih lanjut, perilaku pengeluaran menunjukkan bahwa bagian yang dikeluarkan untuk membayar bahan makanan sangat tinggi. Sebagian dari komponen biaya produksi disubsidi oleh pemerintah, sehingga sangat membantu nelayan dan pembudidaya ikan dalam melakukan kegiatan produksi. Komponen biaya yang disubsidi oleh pemerintah yang paling berperan saat ini adalah bahan bakar minyak (BBM) pada perikanan tangkap.

Efektifitas kebijakan pemerintah tentang subsidi pada perikanan dapat dipelajari pada Gambar 4 yang menunjukkan indeks nilai tukar nelayan sejak Januari 2009 sampai Juni 2010 lebih tinggi dari indeks nilai tukar gabungan dan indeks pembudidaya ikan. Indeks nilai tukar pembudidaya ikan cenderung di bawah 100 . Keadaan ini diperkirakan terkait dengan laju peningkatan harga dari input, terutama pakan yang memberi kontribusi rata-rata 60-65\% dari biaya produksi dan jauh lebih cepat dari laju peningkatan harga ikan hasil budidaya. 
Faktor Berpengaruh Terhadap Nilai Tukar Nelayan

Sesuai dengan analisa di atas maka perlu diperhatikan dinamika indeks nilai tukar perikanan terhadap perubahan IHK (inflasi) dan nilai tukar rupiah. Hasil regresi antara Nilai Tukar Perikanan (NTP Gabungan), Nilai Tukar Nelayan (NTP Nelayan), Nilai Tukar Pembudidaya (NTP Pembudidaya) dengan laju inflasi bulanan (IHK) dan nilai tukar rupiah dapat diperhatikan pada Tabel 3.

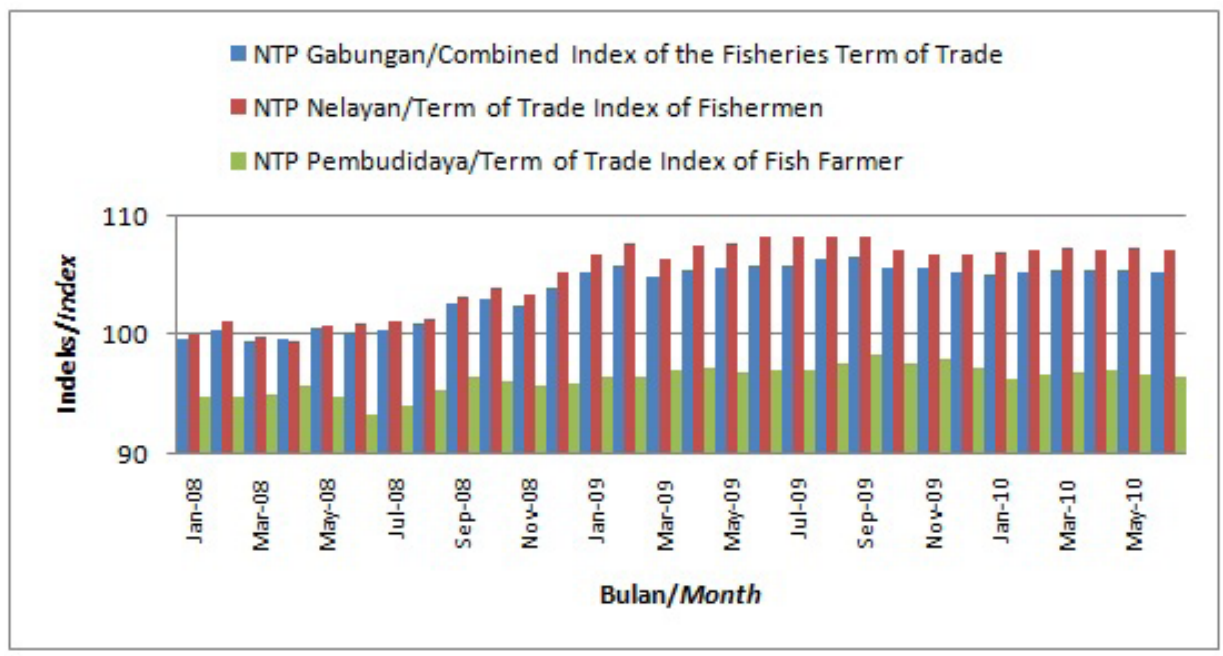

Sumber: BPS (berbagai Terbitan)

Sources: Central Bureau of Statistics-CBS (Various publications)

Gambar 4. Indeks Nilai Tukar Perikanan Januari 2008 sampai Juni 2010 Figure 4. Fisheries Term of Trade Index Form in January 2008 to June 2010

Tabel 3. Rekapitulasi Hubungan antara Indeks Nilai Tukar Perikanan dengan IHK dan Nilai Tukar Rupiah di Indonesia, 2008-2009

Table 3. Recapitulation Relationship between Fisheries Term of Trade Value with the CPI and Exchange Rate in Indonesia, 2008-2009

\begin{tabular}{|c|c|c|c|c|}
\hline No. & $\begin{array}{l}\text { Variabel tidak bebas/ } \\
\text { Dependent variables }\end{array}$ & $\begin{array}{l}\text { Intersep/ } \\
\text { Intercept }\end{array}$ & $\begin{array}{c}\text { Variabel bebas/ } \\
\text { Independent variables }\end{array}$ & $\mathbf{R}^{2}$ \\
\hline 1 & NTPG & $\begin{array}{c}68,6578 * * * \\
(13,25)\end{array}$ & $\begin{array}{c}0,2735 \mathrm{IHK}^{* *}+0,0004 \text { NTRP } \\
(5,26)\end{array}$ & 0,6825 \\
\hline 2 & NTPN & $\begin{array}{c}61.2750 * * * \\
(9,12)\end{array}$ & $\begin{array}{c}0,3367 \text { IHK** } \\
(5,00) \\
(1,25)\end{array}$ & 0,6653 \\
\hline 3 & NTPB & $\begin{array}{c}82.6875^{* *} \\
(22.84)\end{array}$ & $\begin{array}{c}0,1174 \mathrm{IHK}^{* *}+0,00005 \text { NTRP } \\
(3,23) \quad(0,19)\end{array}$ & 0,4041 \\
\hline
\end{tabular}

Sumber: BPS (berbagai Terbitan) / Sources: Central Bureau of Statistics-CBS (Various publications)

Keterangan: $n=24$. NTPG = indeks nilai tukar perikanan gabungan, NTPN = indeks nilai tukar nelayan, NTPB $=$ Indeks nilai tukar pembudidaya, IHK = Indeks Harga Konsumen, NTRP = nilai tukar rupiah terhadap dolar Amerika Serikat.

Description: $n=24$. NTPG = Combined Index of the Fisheries Term of Trade, NTPN = Term of Trade Index of fishermen, $N T P B=$ Term of Trade index of Fish farmers, IHK = Consumer Price Index(CPI), NTRP = Exchange rate against the U.S. dollar 
Hasil regresi pada Tabel 3 menunjukkan bahwa variabel peubah bebas hanya mampu menjelaskan antara $40 \%$ sampai $68 \%$ pengaruhnya terhadap dependent variabel. Sisanya dijelaskan oleh variabelvariabel independent lainnya. Pengaruh peningkatan $1 \%$ IHK akan mendorong masing-masing $0,2735 \%$ NTPG, $0,3367 \%$ NTPN dan 0,1174\% NTPB. Hal ini berarti kontribusi inflasi untuk mendorong penerimaan nelayan dan pembudidaya ikan masih positif.

Angka di atas menggambarkan bahwa kenaikan inflasi bulanan secara nasional sekitar 1\% akan mendorong peningkatan pendapatan nelayan secara nasional $(0,2735 \%)$, pendapatan nelayan $(0,3367 \%)$ dan pendapatan pembudidaya $(0,1174 \%)$. Dorongan kenaikan pendapatan yang relatif kecil pada perikanan budidaya disebabkan oleh tingginya kontribusi pakan dalam usaha budidaya. Sementara itu, peningkatan pendapatan nelayan relatif tinggi dibandingkan dengan pembudidaya karena nelayan umumnya menerima subsidi dari pembelian BBM.

\section{KESIMPULAN DAN IMPLIKASI KEBIJAKAN}

Inflasi dan nilai tukar rupiah merupakan faktor yang sangat berperan dalam menentukan dinamika indeks harga yang diterima dan yang dibayar oleh rumah tangga perikanan. Pengaruh inflasi sangat penting dicermati karena $1 \%$ kenaikan inflasi akan mendorong peningkatan harga yang diterima lebih besar dari harga yang dibayar oleh rumah tangga perikanan.

Dengan demikian untuk meningkatkan kesejahteraan nelayan dan pembudidaya ikan pemerintah harus melakukan intervensi pada komponen pembentuk harga yang dibayar konsumen. Intervensi tersebut dapat dilakukan melalui kebijakan harga pada beberapa faktor produksi, harga barang konsumsi yang dominan diperlukan konsumen rumah tangga perikanan.
Kebijakan intervensi harga perlu dilakukan, karena orientasi pasar produk yang dihasilkan nelayan dan pembudidaya ikan sangat berbeda. Pasar ikan produksi pembudidaya lebih banyak dipasarkan untuk pasar domestik, dan pasarnya terkonsentrasi pada kota-kota tertentu saja. Ikan hasil perikanan tangkap laut selain untuk memenuhi kebutuhan dalam negeri,ada juga yang diekspor. Oleh sebab itu harga ikan hasil budidaya sangat ditentukan oleh volume penawaran dan permintaan ikan. Implikasinya, harga ikan hasil budidaya cenderung lebih rendah dari harga ikan hasil tangkapan di laut. Harga ikan dipasar ekspor didasarkan pada mata uang Dolar Amerika Serikat. Fluktuasi nilai tukar Dolar Amerika Serikat pada tingkat tertentu akan mempengaruhi harga ikan yang diterima rumah tangga perikanan terutama nelayan.

Intervensi kebijakan terhadap harga yang dibayar oleh rumah tangga perikanan perlu dilakukan karena kebijakan untuk mengintervensi harga yang diterima nelayan dan pembudidaya ikan sulit dilakukan sebab produk hasil perikanan terdiri dari berbagai spesies/jenis dan ukuran, serta kualitasnya belum ada standar yang baku.

\section{DAFTAR PUSTAKA}

Annonimous. 2009. Statistik Harga Konsumen Perdesaan di Indonesia. BPS Jakarta.

2009. Indeks Produksi Perikanan Menurut Provinsi Tahun 2005-2009. BPS Jakarta.

2009. Statistik Perusahaan Perikanan Tahun 2008-2009. BPS Jakarta.

2009 Statistik Pelelangan Ikan Tahun 2008-2009. BPS Jakarta.

2009. Indikator Ekonomi. Buletin

Statistik Bulanan. BPS Jakarta 2010. Produksi Perikanan Laut yang

Dijual di TPI Tahun 2009. BPS Jakarta. 
2010. Statistik Ekspor Bulan September 2010. Buletin Statistik Perdagangan Luar Negeri. BPS Jakarta.

2010. Statistik Ekspor Bulan Agustus 2010. Buletin Statistik Perdagangan Luar Negeri. BPS, 2010. Statistik Impor. Buletin Statistik Perdagangan Luar Negeri. BPS Jakarta. 2010. Statistik Harga Produsen Sektor Pertanian Di Indonesia. BPS Jakarta. Statistik Nilai Tukar Petani di Indonesia. BPS Jakarta.

Anwar, A.F., Kasryno, F., Ibrahim, S. dan B. Bachtiar, 1981. Studi kebijaksanaan Nilai Tukar Komoditi Pertanian. Laporan Penelitian. Kerjasama Pusat Penelitian Agroekonomi dengan Departemen IImu-IImu Sosial Ekonomi, Fakultas Pertanian, Institut Pertanian Bogor. Bogor.

Cuddington, J.T. and Urzua, C.M. 1989. Trends and Cycles in the Net Barter Terms of Trade: A New Approach. The Economic Journal, 99 (June 1989): 426-442.

Grilli, E.R. and Yang, M.C. 1988. Primary Commodity Prices, Manufactured Goods Prices and the Terms of Trade of Developing Countries: What the Long Run Shows, the World Bank Economic Review 2 (January 1988): 1-48.

Hutabarat, B. 1995. Dinamika Nilai Tukar Petani dan dampaknya terhadap Pelestarian Swasembada Beras dan Pangan Lainnya. Laporan Hasil Penelitian. Pusat Analisis Sosial Ekonomi dan Kebijakan Pertanian. Badan Penelitian dan Pengembangan Pertanian. Departemen Pertanian.

Pramonosidhi. 1984. Tingkah Laku Nilai Tukar Komoditi Pertanian pada Tingkat Petani. Kerjasama Puslit Agroekonomi dan Universitas Satya Wacana, Salatiga.

Prebisch, R. 1964. The Economic Development of Latin America and Its Principal Problems, In G.M. Meier (ed). Leading Issues in Development Economic. Oxford Univ. Press. New York.
Rahmat, M. 2000. Analisis Nilai Tukar Petani Indonesia. Program Pasca Sarjana. Institut Pertanian Bogor. Bogor.

Reksasudharma, C. 1989. Sistem Pengukuran Nilai Tukar Pertanian Subsektor Tanaman Pangan. Jurnal Ekonomi I (3) : 1-23. Fakultas Ekonomi, Universitas Indonesia. Jakarta.

Simatupang, P dan M. Maulana. 2007. Kaji Ulang Konsep dan Perkembangan Nilai Tukar Petani Tahun 2003-2006. Pusat Analisis Sosial Ekonomi dan Kebijakan Pertanian. Badan Penelitian dan Pengembangan Pertanian. Departemen Pertanian. 19 Hal. . Jakarta

Simatupang, P. 1992. Pertumbuhan Ekonomi dan Nilai Tukar Barter Sektor Pertanian. Pusat Penelitian Soisal Ekonomi Petanian, Jurnal Agroekonomi. Bogor. 11 (1): 37-50.

Simatupang, P. dan B. Isdiyoso. 1992. Pengaruh Pertumbuhan Ekonomi Terhadap Nilai Tukar Sektor Pertanian: Landasan Teoritis dan Bukti Empiris. Ekonomi dan Keuangan Indonesia, 40 (1): 33-48.

Singer, H.W. 1984. Terms of Trade Controversy and The Evolution of Soft Financing: Easy Year in the UN: 1947-1951, In M. Meier and D. Seers (Eds), Pioneer in Development. Oxford Univ. Press. New York

Soeharjo, A. 1976. Nilai Tukar Hasil-Hasil Pertanian Selama Pelita I. Departemen Sosial Ekonomi, Fakultas Pertanian, IPB, Bogor.

Spraos, J. 1980. The Statistical Debate on the Net Barter Terms of Trade Between the Primary Commodities from Developed and Less Developed Countries. World Development, 13 (July 1985): 805-817.

Sukarja R., T. Sendjaja. dan A. Sudradjat. 1981. Studi Kebijaksanaan Nilai Tukar Komoditi Pertanian. Kerjasama Puslit Agro Ekonomi dengan Fakultas Pertanian. Universitas Padjadjaran Bandung. Bandung 